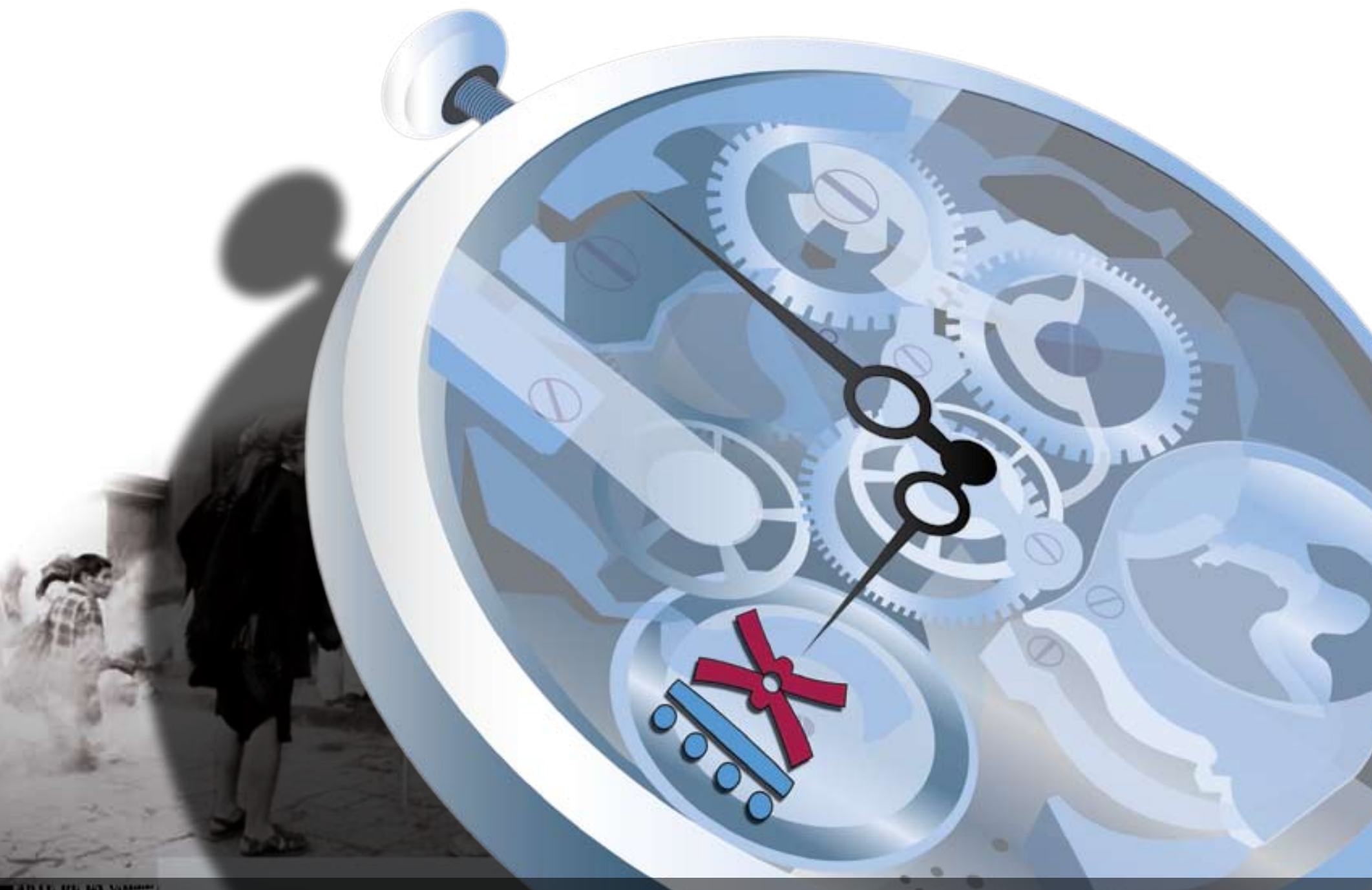

$9^{\circ}$ CONGRESO 2. CENTROAMERICANO DE H IS T O R I A

Universidad de Costa Rica ISSN 1409- 469X

Fecha de recepción: 15 de mayo 2008 Fecha de aceptación: 30 de mayo 2008

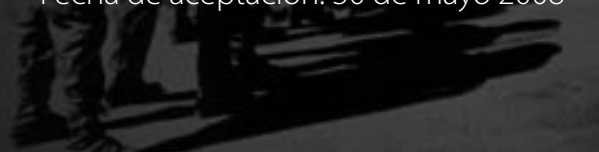

\section{Mestizaje, identidad e historia en América} Latina.

Miembros del Consejo Editorial:

Dr. Ronny Viales, Dr. Juan José Marín

Editores Técnicos:

Allan Fonseca, Andrés Cruz, Gabriela Soto
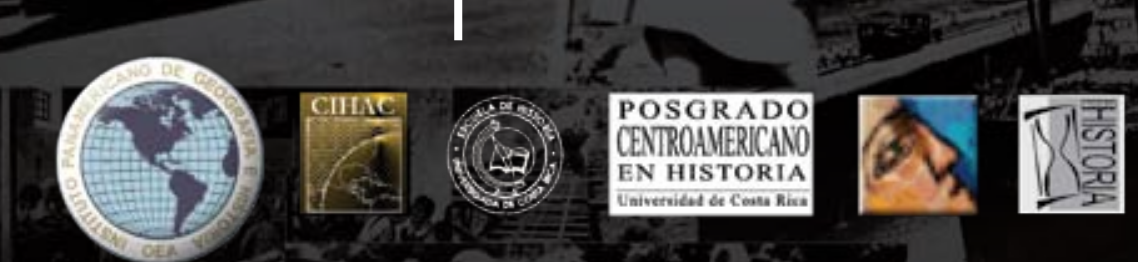
Indexaciones: Repositorio de Revistas UCR, DIALNET, Latindex, REDALYC Directorio y recolector de recursos digitales del Ministerio de Cultura de España, Directory of Open Access Journals. Diálogos Revista Electrónica de Historia ISSN 1409- 469X. Número especial 2008. Dirección web: http://historia.fcs.ucr.ac.cr/dialogos.htm

\section{Mestizaje, identidad e historia en} América Latina.

Jorge Bracho.

Profesor - Investigador de la Universidad Pedagógica

Experimental Libertador - Instituto Pedagógico de

Caracas. Coordinador del Centro de Investigaciones

Históricas Mario Briceño Iragorry. E - mail: jorbrec59@ gmail.com; jorbrac59@hotmail.com. 


\section{Introducción.}

Desde inicios republicanos los distintos espacios territoriales que alcanzaron su independencia, política y administrativa de la Corona española, debieron emprender fórmulas políticas, sociales y culturales con las que intentaron definir los atributos de los nuevos territorios ahora soberanos e independientes. Está claro que este cometido se hizo en estrecha confrontación con la España monárquica. La necesidad por mostrar rasgos de particularidad y excepcionalidad encontró en los distintos letrados, publicistas y académicos, el vaso comunicante entre éstos y un público lector al que se buscaba convencer acerca de la nueva estética por construir. No se trató de una realidad devenida inevitablemente. La opción por la patria, el territorio y la nación fue la que se hizo hegemónica en el período posindependentista, ante las proposiciones de confederación dejadas de lado por parte de las elites que tomaron las riendas del poder político en este tiempo.

Al romper lazos administrativos y políticos con la monarquía absoluta, el requerimiento narrativo navegó por las procelosas aguas de la construcción del pueblo y una nueva ciudadanía. Al lado del reconocimiento del ejercicio ciudadano para todos, tal como quedó establecido en la constitución venezolana de 1811, se agregó el de un conjunto de relaciones culturales arraigadas desde los tiempos coloniales. Relaciones en las que la negación del otro, el mestizo, marcaron el destino del excluido, jurídica y culturalmente justificadas, en los tiempos de la modernización de la Hispanoamérica decimonónica.

Estudiar el caso del mestizo y del mestizaje en la hoy denominada Latinoamérica o América Latina, tal como se haría dominante denominarla en el último tercio del siglo XIX, concita a volcar la mirada en los contenidos de las voces mestizo y mestizaje. Aunque, también, su estudio guarda estrecha relación con los usos que se han difundido de los mismos, en las 
distintas narrativas que han buscado con afán atributos con los cuales caracterizar en términos culturales a la América Latina. De ahí pues la necesidad de hurgar en la connotación histórica otorgada a los términos mestizo, mestizaje y mestizar, propuestas desde el canon occidental y las narrativas tramadas desde la periferia al amparo del espacio occidental y la mundialización cultural.

No se trata, desde luego, de un juego de palabras. Mi intención es la de ofrecer un esbozo panorámico, en el que estos términos han sido utilizados. La ambigüedad, con la que el término mestizo ha estado investido, hace imperiosa su delimitación en la mixtura, la combinación, el amalgamiento, la síntesis, que van más allá de trazas orgánicas, y que se adentran en atributos culturales con los que se intentó desdibujar lo que del mestizaje se había ofrecido como narrativa moderna. Por esta sencilla razón, es importante analizar el estatus de uso concedido por distintos narradores, durante gran parte del siglo XX, al mestizaje y sus adherencias. Todo ello bajo un trasfondo de la senda occidental y la mundialización de la cultura.

Como se sabe, a partir del siglo XVI se inaugura una nueva conformación sistémica al amparo del capitalismo mercantilista, basada en la relación colonial. También es conocido que el proceso histórico social inaugurado en la fecha anotada, estuvo acompañado de tropelías, imposiciones, inequidades y desigualdades; pero, es también necesario reconocer las nuevas hibridaciones y combinaciones culturales que tuvieron como escenario al Nuevo Mundo.

Hacer referencia a éste remite, necesariamente, a la expansión de Occidente, así como al proceso cultural que lleva como impronta su presencia en espacios territoriales distintos a su lugar de origen. Lo que se conoce como mundialización cultural no significa la presencia de una cultura mundial, al contrario refiere la propagación de valores, creencias y representaciones no sujetas a un territorio específico. No se trata de una experiencia cultural simétrica; se 
trata de apropiaciones culturales que se galvanizan en diferentes espacios del sistema mundo capitalista.

El mestizaje, al que me refiero en esta oportunidad, forma parte de esa mundialización dentro de la occidentalidad. La recurrencia a Occidente y sus inherencias, no se encuentra atada sólo a las ejecutorias relacionadas con la conquista y la colonización de América. Esto es así porque el reclamo de occidentalidad es una constante entre una gran porción de letrados y ensayistas hispanoamericanos, los que si bien es cierto reconocieron el mestizaje como una peculiaridad continental hispanoamericana, no lo es menos su fuerte disposición por demostrar el carácter fuertemente occidental de América.

La importancia que le fue otorgada, por distintos académicos, a la conformación del Ser hispanoamericano, no sólo pasa por el desarrollo económico y político de las sociedades del orbe. Se encuentran elementos en juego, propios del mestizaje que comienzan a emerger como segmento fundamental del proceso de formación ciudadana y social.

Es necesario remitirnos a lo cultural porque es en este espacio histórico y social donde hábitos y costumbres, arraigados en el tiempo, han venido atentando contra toda fórmula de cambio y transformación. Tanto los que dicen defender la tradición, por intermedio del nacionalismo, como quienes se asumen defensores de la modernización, tienden a eludir lo cultural. Parece más bien que lo que la cultura ha implicado sirviese sólo como ideología, en su sentido de falsa conciencia. Ora con fines de preservar posiciones políticas y sociales. Ora por proponer cambios supeditados a aspiraciones de poder. Lo cultural no sólo ha de servir como forma de adjetivar o medio taxonómico, sino como un eslabón al servicio de un verdadero cambio que comprenda nuevos hábitos y nuevas formas de asociación entre los actores sociales. No es sólo la búsqueda por allanar sendas de percepción, lo necesario estriba en inéditos caminos donde la asociación 
de los actores sociales no se encuentre supeditada a formas patrimoniales.

Lo que en 1935 el venezolano Mariano Picón Salas llamó el misterio americano guarda estrecha relación con lo anotado anteriormente. Es decir, la lucha por establecer fuera de "impurezas" lo que la modernidad venía ofreciendo como ideal y una realidad cargada de hábitos y costumbres arraigadas en el tiempo. El conflicto civilización - barbarie ha sido el argumento predilecto en las narrativas ficcionales tramadas por distintos letrados hispanoamericanos, desde el siglo XIX. Por ello, no parece errado afirmar que uno de los más grandes problemas del letrado hispanoamericano comprende la búsqueda por negar su propio mundo, al lado de elucubraciones alrededor de la presencia de una homogeneidad cultural, que, a todas luces, es irreal.

En fin, la importancia otorgada al mestizaje, como categoría histórica o corte de la realidad, no confluye únicamente con el firme propósito de establecer un hecho histórico, cuyo filón de mayor trascendencia se encuentra en la constitución de un nuevo actor social. Quizá lo más importante sea su vinculación con Occidente, cuyo gozne de articulación se presentó por medio del mundo ibérico, con el que América Latina ingresó a la civilización occidental.

Modernidad, raza y mestizaje.

Un hecho importante en cuanto al uso del término raza viene a tono con un contenido que rebasaba la pigmentación de la piel. Cuando se le utilizaba, dentro de las intenciones por establecer nuevos espacios de la memoria, a fines del decimonono se presentó como civilización. Esta tesitura muestra cómo los procesos de enriquecimiento conceptual se presentan en la medida que el requerimiento narrativo así lo exige. Requerimiento o necesidad que responden a situaciones específicas de momentos del devenir. La raza, o su contenido, comienzan a ser percibidas como un modo de comprender la vida de los actores sociales, amén de un pasado común y la proyección de futuro. Es preciso indicar, en este sentido, que la noción de raza 
tuvo un uso equivalente al de carácter nacional. Se presentó así un hecho en torno a un término que, en un primer momento, tuvo un fuerte componente biológico y orgánico, para pasar luego a hacer referencia a bases étnicas e influencia geográfica.

Es preciso indicar que, tanto la hispanidad como el hispanismo, provenientes de España o América, hicieron suyos dos componentes básicos del carácter nacional o la raza: la historia común y el idioma. Fueron estos dos componentes de la cultura a los que se otorgó un papel preponderante, dentro de las diversas narrativas que intentaron definir una nueva configuración histórica en el espectro de la modernidad. Por esto es posible encontrar, en las narrativas modernas, el convencimiento de que la nacionalidad, o personalidad de los pueblos, estaba constituida por la raza, la lengua y la historia. Tesitura que serviría de sustento a las narrativas de españoles e hispanoamericanos para con ella demostrar y convencer acerca del hecho, tenido por cierto, de un origen y devenir común.

Desde este dintel, se puede argüir que estamos en presencia de una respuesta clara ante lo divulgado por el conde Arthur de Gobineau. El mito de la raza superior, la aria, fue difundida por este escritor francés ante la propuesta difundida, años antes, por Thomas Carlyle acerca del mito del héroe. Si el positivismo latinoamericano se vio alimentado por las propuestas de Gobineau, al igual que de otros como Gustave Le Bon, aunque con matices que desdicen su fuerte disposición homogenizadora ${ }^{1}$, no lo son menos las respuestas provenientes de diversos letrados, publicistas e intelectuales, que se vieron en la imperiosa necesidad de demostrar que la raza hispana no era un grupo étnico e histórico ajeno de toda disposición civilizatoria. Sin embargo, debe ser admitido que el contenido del término mestizo desde, por lo menos, el siglo XVI se ha mostrado en atingencia con una combinación biológica plagada de incertidumbres,

1 Pablo Guadarrama, Positivismo y antipositivismo en América Latina (La Habana, Cuba: Editorial de Ciencias Sociales, 2004), 57. 
rarezas y, como corolario de éstas, propia de suspicacia. Carmen Bernard ${ }^{2}$ ha propuesto que a los mestizos se les consideró como "desnaturados" en virtud de su deslealtad originaria “... porque sirven a dos señores naturales: al rey de España y al señor indígena, y pueden manejar dos códigos sociales diferentes. De ahí que los mestizos estén siempre vinculados con la posibilidad de atravesar fronteras - políticas, geográficas o culturales...”. Una primera aproximación al contenido de la palabra mestizo y la propia de mestizaje aparece cargada de incertidumbres, porque históricamente se le ha asociado con impureza. Impureza a la que es dable relacionar con una carencia de síntesis, en la que, además, no es posible dilucidar las pulsaciones primigenias de actuación del mestizo. La mixtura consumada en éste, se estableció como lectura de un proceso cuyo carácter se ha representado por medio de su asociación con corrupción y falseamiento.

Durante el siglo XVII, el término mestizo implicaba: "El que es engendrado de diversas especies de animales; del verbo misceo es, por mezclarse"³. El tratamiento que se prestaba al vocablo animal hacía referencia a una sustancia animada, en especial, a los seres humanos por contar con el uso de la razón. La indicación inicial del término mestizo se concentró en la mixtura y el carácter de mixto, así como en el ayuntamiento entre hombre blanco e india. En el Diccionario Enciclopédico Hispano - americano de literatura, ciencias y artes, de 1897, se estableció que mestizo: “Aplicase a la persona o animal nacido de padre y madre de diferentes castas. Dícese con especialidad del hijo de europeo ú hombre blanco y de India"4. Dentro del canon occidental, durante el siglo XX, esta connotación de mestizo ha persistido, tal como se 2 Carmen Bernard, "Mestizos, mulatos y ladinos en Hispanoamérica: un enfoque antropológico de un proceso histórico", en Motivos de la antropología americanista. Indagaciones en la diferencia, coor. Miguel León - Portilla (México: Fondo de Cultura Económica, 2001), 122.

3 Sebastian de Covarrubias, Tesoro de la lengua castellana o española (Barcelona - España: S.A. Horta, I.E., 1943), 802. (Primera edición: 1611).

4 Diccionario enciclopédico de literatura, ciencias y artes (Barcelona - España: Montaner y Simón, editores, 1897), 933: XVII. 
puede apreciar, en la segunda edición del Diccionario Enciclopédico Salvat, en él se lee, mestizo: “Aplicase a la persona nacida de padre y madre de raza diferente, y con especialidad al hijo de hombre blanco e india o de indio y mujer blanca..."5.

Se puede apreciar que, a partir de lo expresado hasta ahora, existía el reconocimiento de un nuevo tipo humano representado en el mestizo, lo que no quiere decir que esta nueva expresión de mixtura envolviera un nuevo actor social investido de virtudes. Se reconoce, sin lugar a dudas, un nuevo ser social y cultural, pero cuyo origen induce a pensar en un desliz de virtudes primigenias. En vez de apreciar en la mixtura una riqueza humana y cultural se ató con alteración, porque se pensaba que la pureza de sangre era la verdadera expresión de la virtud, la belleza y lo normal. Lo expresado se puede visualizar en el contenido que se otorgó al término mestizar que, en los diccionarios mencionados, aparece sin mayores variaciones. Mestizar: “Corromper ó adulterar las castas por medio del ayuntamiento o cópula de individuos que no pertenecen á una misma”.

Lo cierto del caso es que con el término mestizaje se otorgó un estatus de uso a un acontecimiento cultural e histórico, con el que se buscaba señalar: “...la hibridación espontánea y natural de la especie humana, debido al cruzamiento entre las distintas variedades o razas que la integran..."7. Sería en el diccionario publicado bajo la rubrica Salvat donde se advertía que la denominación mestizos señalaba una mixtura humana, la que servía para la diferenciación con las especies animales. Desde el siglo XIX el mestizo dejó de tener existencia en la legislación posindependentista, con lo que se galvanizó dentro de las categorías de pueblo y de ciudadanía. No obstante, el uso del término puede provocar confusiones en virtud de las ambigüedades, en especial legales, con las que hoy podemos leer su presencia en la historia desde tiempos 5 Diccionario enciclopédico Salvat (Madrid: Salvat editores, 1943), 291: IX.

6 Ibid.

7 Ibid, 290: IX. 
coloniales. Esto es así, porque lo que pudiéramos denominar primer mestizaje, el de español con india, se diluye con el propio de trigueño, pardo o mulato. Lo que si parece ser cierto es que las diferencias entre castas, se presentó por la vía jurídica más que por el color de la piel. Sin embargo, los mestizos coincidieron con el criollo amén de algunas prerrogativas otorgadas, por la corona española, respecto a la exoneración tributaria en los espacios territoriales de la América colonial. Igualmente, se les otorgó un estatus, similar al concedido a los mulatos, con quienes se les comparaba por vivir “apartados y desviados”, o sea, “...libres, sin que sobre ellos recaiga el control social del pueblo y de la comunidad..."

El sentido de la mestización también se mostraba por provenir de una naturaleza distinta. Naturaleza que se pensaba exótica y devoradora de hombres y que, por ser tal, determinaba en los criollos cambios ajenos a su composición orgánica. La mezcla y la mixtura que se venía gestando desde el siglo XVI despertaban suspicacias entre las autoridades imperiales, similar tesitura a la experimentada por España, para la misma época, frente a los moriscos y judíos. Las ideas de naturaleza y natural, en las que se situó a los indígenas, indicaban el lugar de nacimiento y, también, una huella y traza de origen. Al amparo de esta disposición gnoseológica, al mestizo se le consideró un ser humano que compartía con los indígenas una misma naturaleza, con la que se había conformado su temperamento, su manera de actuar y atributos, las que, a su vez, había obtenido por la vía materna (indígena). De igual manera, los españoles que habían nacido en el Nuevo Mundo despertaban suspicacia entre las autoridades coloniales, porque se creía que el roce y la experimentación en otras latitudes climáticas y territoriales constreñían al español a mestizarse, o lo que es lo mismo a hibridarse con las condiciones geográficas y culturales del Nuevo Mundo.

De este modo es que ha de estudiarse el conjunto de categorizaciones que sirvieron de 8 Bernard, 123. 
referencia para clasificar al otro, el no peninsular. Estas categorías no sólo se apoyaron en el color de la piel, también refieren el ámbito cultural, porque se agregaron otros elementos que tenían como propósito sustentar las nuevas categorizaciones y taxonomías. Las diversas categorías de mestizo, zambo, mulato, pardo, criollo y otras de la misma estirpe, constituyeron el esquema establecido para la clasificación, la taxonomía y la jerarquización dentro del orden y la estabilidad en la sociedad colonial. Aunque el mestizo dejó de poseer existencia jurídica en el decimonono, ello no significó que las representaciones simbólicas respecto al mestizaje y sus inherencias, configuradas en los tiempos coloniales, desaparecieran del mundo de las mentalidades y del espacio cultural. El racismo, por ejemplo, adquirió notoriedad y nuevos bríos con la liberación del marco jurídico y normativo colonial. Liberación que se ejecutó bajo el influjo de las leyes modernas liberal republicanas, en las que la noción de ciudadanía pretendió establecer iguales derechos para todos.

Lo hasta ahora esbozado sirve de marco para comprender y visualizar cómo el contenido del término mestizo adquirió fisonomía, aunque, igualmente, se fue plagando de inéditos contenidos en consonancia con las nuevas tendencias teóricas, políticas y sociales que venían germinando en Hispanoamérica, en el ámbito de lo que hoy denominamos identidad. Ya desde el Plan de Ayutla (1854), propuesto en México, el mestizo adquirió una nueva representación porque se visualizó que los habitantes mayoritarios de esta nación mesoamericana eran mestizos. La idea del mestizaje que se comenzó a hacer hegemónica en el mundo académico hispanoamericano, durante el siglo XX, se avino con la búsqueda por mostrar el carácter de excepcionalidad, particularidad y originalidad continental. Esta disposición, que pugnaba por su hegemonía, surgió como respuesta a las tesis que se habían encargado de divulgar que los orígenes hispanoamericanos sólo tenían su correlato en el mundo indígena. Lo cierto del caso 
es que la idea de mestizaje que se fraguó en el siglo XX, propuso que el origen y continuidad histórica latinoamericanos debían su existencia a los avatares coloniales, heredad del espíritu, tradición, usos y cultura del período colonial.

Lo que se conoce con la denominación hispanismo, en su vertiente narrativa, se estructuró ante las ideas surgidas a partir del panamericanismo y el indigenismo. La fortaleza ante estas propuestas teóricas, fue la reflexión acerca de la identidad latinoamericana. La que se vio beneficiada con la figura del criollo y la idealización del mestizaje, la que, igualmente, se vio enriquecida con los nuevos contenidos asignados a la noción de raza. En fin, el tema del mestizaje, en concordancia con los espacios social y cultural más que biológico (de ahí que se asocie con transculturación y aculturación), se izó como bandera de identificación en América Latina.

El mestizaje muestra a las claras lo que en el orbe latinoamericano connotaba la raza hispana, tal como lo asentara a mediados del siglo XIX el español Emilio Castelar (1832-1899) para hacer referencia a España como la Madre Patria y la América como su hija dilecta, lo que, por demás, indicaba una serie de elementos necesarios para alcanzar un futuro promisor. Las respuestas delhispanismo latinoamericano, se configuraron ante el monroísmo-panamericanismo, propulsado desde los Estados Unidos de Norteamérica, y el indigenismo, cuyo origen se debió a pensadores latinoamericanos. En estrecha relación con el hispanismo, el mestizaje sirvió como una representación de la modernidad, con lo que, a su vez, se intentó el alejamiento de las propuestas del indigenismo en tanto referente inicial de identidad. El hispanismo, dentro y fuera de América Latina, representó e imaginó los peligros, especialmente en términos culturales, representados en el expansionismo del coloso del norte. Lo cierto de todo esto es que la afanosa búsqueda por encontrar las huellas iniciales de la identidad, no sólo se ejecutaron con el utillaje 
teórico - conceptual elaborado en Occidente, también hizo suyo la necesidad de conjugar una genealogía con la cual explicar el origen de la excepcionalidad del Nuevo Mundo, donde las adherencias culturales del mestizaje sirvieron de gozne entre un requerimiento narrativo y el proceso histórico, el de los hechos brutos.

\section{Cultura y mestizaje.}

Sin lugar a dudas, el mestizaje asumido (que bien pudiera ubicarse en el plano ideológico) bajo el influjo moderno se caracteriza por su asimetría. En la que una cultura tendría un carácter natural, de dominio, mientras la otra pierde legitimidad por su propensión a ser dominada. El mestizaje vendría a significar, de este modo, el conflicto que ha implicado la oposición de la cultura blanca respecto a la no blanca. No obstante, un tipo de mestizaje se encumbró, en tanto primigenia nacionalidad. Es el caso verificable tanto en trabajos de ensayistas como de novelistas hispanoamericanos, a saber: el mexicano Ignacio Altamirano, el dominicano Manuel de Jesús Galván, el brasileño José de Alencar, y los venezolanos Mariano Picón Salas y Mario Briceño Iragorry.

Para el caso de la novela latinoamericana, tal como lo ha propuesto Doris Sommer, los "romances históricos" que se considerarían novelas nacionales en sus países de origen, prefirieron casar al héroe con la heroína, independientemente de su origen étnico, con lo que superaron barreras impuestas por las relaciones históricas establecidas como las de pureza sanguínea, la clase social, el género y las diferencias culturales. Luego de las guerras de independencia y de los conflictos suscitados posterior a ellas en el decimonono, se alcanzó un consenso al aceptar la convivencia de grupos culturales disímiles. Lo que no quiere decir que el racismo haya mitigado. Sólo que se aceptó, en el seno de las elites dominantes, la existencia conflictiva con el otro. Existencia que se vio mitigada en las distintas configuraciones narrativas ficcionales, por la 
unión entre actores de diferente origen étnico. Aunque, no debe ser descartada la presentación de matrimonios nacionales ideales, entre blancos e indias. Ejemplo de ello se puede visualizar con doña Mencia en Enriquillo (1882), del dominicano Manuel de Jesús Galván, y Marisela en Doña Bárbara (1929), del venezolano Rómulo Gallegos. De ahí que:

...El ideal del mestizaje, acuñado de manera tan peyorativa en inglés como miscegination (entrecruzamiento), tenía su base en la realidad de una mezcla racial a la que se le atribuían diferentes virtudes y defectos, y que tenía que cuajar en algunos países si había de producirse algo parecido a la unidad nacional...9

Es justo considerar que, en gran parte del siglo XX, el mestizaje ha sido concebido al alimón con la idea de América Latina y la pertenencia occidental. Tanto la idea de latinidad como el convencimiento de vivir en un otro Occidente, se galvanizaron en la conformación de las identidades nacionales, luego de los procesos de independencia.

... Los "mestizos" empezaron a reclamar su derecho al espacio del que se habían apropiado las elites criollas tras la independencia. Es curioso que el mestizaje se convirtiera en un ideal para lograr la homogenización de las identidades nacionales. No obstante, el mestizaje fue siempre un espejismo, pues la mezcla de sangre no fue de la mano de una mezcla de cosmologías (epistemologías). Los "latinos" de América, criollos o mestizos, siempre abogaron por el paradigma de lo novedoso y conservaron los lazos con su remoto "origen" europeo, pero nunca defendieron sus orígenes indígenas... ${ }^{10}$

9 Doris Sommer, Ficciones fundacionales. Las novelas nacionales de América Latina (Colombia: Fondo de Cultura Económica, 2004), 111.

10 Walter Mignolo, La idea de América Latina. La herida colonial y la opción decolonial 
Como una corriente dentro del mestizaje, el racismo se ha convertido en una categoría histórica. Al interior de la clasificación blanco / no blanco se configuró la idea del mestizaje y el espacio cultural latinoamericano. El lado blanco, por ejemplo, comprendería el lado "oficial" y positivo de la actuación cotidiana, en la que cabría el abrazo a la modernidad y la modernización al estilo euro - estadounidense. Mientras, en el lado no blanco encuentra lugar la otredad, la tradición, hábitos y costumbres populares y ciertos usos del lenguaje no avalados por la Real Academia Española. Pero también, a través del lenguaje es posible rastrear signos y significados de identidad. El venezolano Enrique Bernardo Núñez establecería que, en la lengua de los conquistadores habría de expresarse la raza americana ${ }^{11}$, al igual que Picón Salas, la lengua heredada del colonialismo ibérico ayudaría a revelar el secreto de la identidad hispanoamericana.

... Está envuelto en el misterio semántico de nuestro castellano criollo, mulato e indígena, absorbedor de nuevas esencias y forjador de palabras, ese castellano de los 'americanismos' en que se han grabado las vivencias y las metáforas del aborigen en la lengua importada y del español en un mundo distinto; se expresa en música, ritos, fiestas y danzas...por eso contra el hispanismo jactancioso y contra el indigenismo que quería volver a la prehistoria, la síntesis de América es la definitiva conciliación mestiza ${ }^{12}$.

(España: Gedisa editorial, 2007), 156.

11 Enrique Bernardo Núñez, Novelas y ensayos (Caracas, Venezuela: Biblioteca Ayacucho, 1986), 107.

12 Mariano Picón Salas, De la conquista a la independencia (México: Fondo de Cultura Económica, 1994), 49-50. 
Con el uso de la lengua aparece la condición mestiza al momento cuando, por ejemplo, se apela a algunas palabras, las cuales vienen cargadas de una bipolaridad, binarismo y antinomia. Así se puede rememorar el uso de racional, civilizado, gente o civil; frente al uso de irracional, salvaje, bárbaro, tierrúo o militarista. El otro, la otredad, se encuentra encubierto dentro de estos últimos calificativos. El otro deviene así en un ser temible y representante de las tradiciones más oscuras ante las bondades de la modernización y el progreso.

Rosalba Campra ha señalado que la literatura ha otorgado forma y respuestas a la pregunta que América Latina se plantea, desde los primeros años de la colonización y la conquista ibéricas,

... ¿con qué palabra nombrar, nombrarse? ¿La palabra introducida por España, legal y canónica, pero también impúdicamente ajena respecto a la realidad; o bien la palabra propia, pero que fuera de un espacio restringido carece de resonancia, y obliga los textos a la lamentable muleta de la nota al pie de página del vocabulario final? ${ }^{13}$ (P. 107).

En lo anotado, con anterioridad, no sólo se está haciendo referencia a la palabra impresa o la lengua escrita y hablada. También se refiere a la falta de reconocimiento del lenguaje, todavía en el siglo XX llamado dialecto, porque se ha asociado con oralidad, desde el canon occidental. Ejemplo de palabras todavía exóticas para puristas de la lengua y de uso sarcástico en el mundo académico, puede precisarse en términos como piache, caudillo, tribus, mexicas o cemíes, que connotan un correlato y hechos brutos, pero que aún continúan refiriendo sólo lo profano o algo ya devenido. Aún, más importante, es el hecho del desconocimiento del objeto al que se refieren

13 Rosalba Campra, América Latina: la identidad y la máscara (México: Siglo XXI editores, 1998), 107. 
las palabras tal como se puede corroborar con la Ceiba, árbol denominado de este modo por los esclavos y los descendientes afroamericanos en Cuba. A lo desconocido se le endosan atributos y características que luego justificarán el nombre asignado. Así puede visualizarse en el caso de nombres utilizados para identificar lugares específicos Venezuela, Nueva Cádiz, Nueva Segovia, Nueva España, también a frutos de la tierra como el pomodoro, papa de oro, adjudicado al tomate. Por tanto al otro, por ser otro, se le atribuyen cualidades y especificidades en las que se pueda sustentar el significado de lo nombrado. De igual forma, el uso del lenguaje no es sólo la demostración de una existencia exótica, es también un vaso comunicante de nuevas modalidades de identidad. El mestizaje y sus concomitancias pueden ser leídos desde este ángulo.

Al ser nuestras sociedades mestizas, el mestizaje se encuentra cargado de virtualidad. Esto es así porque se puede dejar de ser no blanco mediante el blanqueamiento. Proceso que es posible amén de ejecutorias económicas. Un ejemplo histórico es el de la Real Cédula de Gracias al Sacar, establecida, no exenta de conflictos, especialmente en Venezuela, por parte de la Corona Española en el último tercio del siglo XVIII, en 1795 para ser más precisos. Mediante esta real cédula el Rey otorgaba la calidad racial y el soberano decretaba que se tuviera por blanco a aquel que así lo pidiera, previo pago en monedas. En los tiempos actuales pudiera pensarse el blanqueamiento amén de elementos simbólicos como el dinero, el prestigio, el nivel de instrucción y la acumulación de bienes, en tanto su pérdida implicaría la existencia en el mundo no blanco (léase: indio, negro, zambo, culí, niche, mono), es decir, la falta de propiedades, reconocimiento o dinero, simplemente. Durante gran parte del siglo XIX, a la luz de las teorías racialistas en boga, como el darwinismo social y el organicismo, el mestizaje se vio revitalizado como connotación negativa. Quizá, esta disposición no debiera sorprender, porque amén del culto a la raza, divulgada por el francés Arthur de Gobineau, la idea de mestizaje adquirió ese 
matiz negativo. Usualmente escuchamos o leemos que el mestizaje no fue bien visto en gran parte de Europa. Sin embargo, en los espacios poscoloniales de América adquirió, en ciertas narrativas, un cariz celebratorio.

Las configuraciones respecto al mestizaje durante gran porción del siglo XIX, fueron parte de la visión divulgada desde los centros de poder mundial, visiones que hicieron suya publicistas y letrados de este tiempo. Sólo así es posible comprender escritos tardíos de Juan Bautista Alberdi, Domingo Faustino Sarmiento, Carlos Octavio Bunge, Alcides Arguedas, Francisco García Calderon y Laureano Vallenilla Lanz. Los cuatro últimos mencionados, así como las configuraciones narrativas, por ellos tramadas, corresponden al siglo XX. Aunque, indican una tradición de pensamiento, dentro del liberalismo conservador que estos letrados difundieron. Sus tesis giraron alrededor de la necesidad del hombre fuerte en el manejo de la cosa pública y los requerimientos de un funcionamiento económico, con un trasfondo de libertad ante el Estado.

Uno de los grandes bemoles con los que las elites locales hispanoamericanas se toparon, fue la construcción de pueblos, amén del otorgamiento de ciudadanía. Sólo que se buscó llevar a cabo este cometido en sociedades cuyo trasfondo social estaba sustentado en la etnización del trabajo, como la esclavitud y el biopoder. Además, debe tenerse en cuenta como un hecho el que, en el mundo de las mentalidades, la discriminación y el racismo han estado presentes a lo largo del tiempo. No cabe duda, que muchos de los conflictos suscitados durante el siglo XIX, en gran parte de Hispanoamérica, tuvieron que ver con la necesidad de reconocimiento de todos aquellos denominados mestizos.

\section{El mestizaje como configuración.}

Una primera aproximación a la cuestión del mestizaje concuerda con su asociación a un 
hecho consumado. La real Cedula de Gracias al Sacar, 1795, pretendió vehicular la pureza de sangre. Aunque, se estaba admitiendo el mestizaje como un hecho cierto. Pero, a la luz de acciones burocrático - administrativas ejecutadas por los borbones, se pretendían reconocer derechos, deberes y obligaciones a la acción ciudadana, con artilugios legales que, si a ver vamos, la misma estructuración social y las mentalidades negaban desde todo plano el reconocimiento del otro.

Si a la idea del mestizaje, como corolario biológico, genotípico y fenotípico se le puede agregar la de un cambio, en este mismo orden, por qué no aceptar los contenidos de aquella real cédula refrendada en 1795, por los capitostes de la Corona española, como el reconocimiento de un nuevo sujeto histórico? Lo cierto del caso es que su ejecución se debió a la necesidad de recursos económicos, también al reconocimiento de una mixtura racial, que podría ser borrada por el blanqueamiento amén de un pago monetario. Es preciso anotar, en este punto, que en Venezuela se presentó un hecho singular de discriminación racial. La singularidad reside en la presencia de canarios blancos a quienes se les negaban ventajas propias de blancos peninsulares y blancos criollos. Si los peninsulares discriminaban a los criollos, éstos, a su vez, lo hacían frente a los canarios. Es viable que esta situación constituya una explicación válida que ayude a aclarar porque muchos de los jefes realistas -Monteverde, Yánez, Morillo- provenían del lado de los canarios. Además, pudiese aclarar que más que racismo por el color de la piel, la discriminación se presentó con un alto contenido económico.

La idea de mestizaje, así como su uso, sugiere, de igual forma, un corte temporal. Porque se asume como un acontecimiento de cruce biológico, al que luego se le reconocerá su contenido cultural, y que tuvo su origen con la inauguración del Nuevo Mundo. Siendo así, se ha pretendido hacer ver que el mestizaje fue propicio en una porción territorial excepcional, dentro del sistema mundo capitalista. Con sólo mirar la historia humana, desde los tiempos greco - romanos, al 
menos, veremos que el mestizaje ha sido y es una forma muy natural de asociación entre los seres humanos. Sólo que en nuestra realidad su uso tuvo un fuerte carácter negativo, tal como puede ser leído en: La cautiva, del argentino Esteban Echeverría y en Facundo, del también argentino Domingo Faustino Sarmiento. El mestizaje y las representaciones que de éste se propusieron, durante el decimonono, confluyen predominantemente dentro de un marco negativo acaecido en tiempos de la colonia. Quizá, el aspecto de mayor altazor comprenda no tanto la mezcla y mixtura en sí misma, sino a los protagonistas de éstas. Así lo harían público Juan Bautista Alberdi, Alcides Arguedas, Carlos Octavio Bunge y José Gil Fortoul, entre otros.

Como tesis es dable sugerir que en el siglo XX la idea, esbozada con anterioridad, comienza a desdibujarse. Sin llegar a desaparecer en los usos narrativos, menos orales, su presencia, en el amplio espectro de las mentalidades, se ha mantenido con otras variantes. Es que acaso el racismo y la discriminación actual hacia afrolatinos e indígenas no es una muestra palpable de ello? En gran parte del siglo pasado es dable encontrar narrativas donde el mestizaje muestra rasgos celebratorios. Esto sugiere una nueva percepción que busca el alejamiento del ojo imperial y del régimen escópico con el que se divulgó la imagen y la representación del mestizaje, por lo menos, durante el siglo XIX y gran parte del XX entre un grueso grupo de ensayistas, publicistas e intelectuales. La nueva percepción, aquella que abrevó en los postulados de la modernidad, la misma que constriñó a ver el mestizaje como desdibujamiento de las potencialidades humanas, se encaminó por otras vías, en el que el mestizaje comenzó a ser visualizado como parte integrante de procesos históricos y culturales.

Lo demuestra así la propuesta de Fernando Ortiz con la noción de transculturación, desde donde algunos ensayistas, etnógrafos y narradores sustentarán sus tesis alrededor del mestizaje. En esta nueva percepción el mestizaje no es asumido como un hecho dado, consumado en el 
tiempo, sino como una mixtura donde el elemento indígena encontró cobijo o nuevos cauces de realización. Es posible que las ideas de José María Arguedas sean las de mayor vigor en este sentido. Es decir, en la mezcla indo - española el aborigen encontró una fortaleza en vez de su debilitamiento.

No es el caso para intelectuales como Franz Tamayo, José Vasconcelos, Mariano Picón Salas y Arturo Uslar Pietri, entre quienes aquel axioma se revierte hacia el mundo ibérico. Sin embargo, para los mencionados lo que si parece haber sido una certidumbre sin fisuras, es la de que el mestizaje proporcionó una individualidad histórica. Individualidad dentro del Hemisferio Occidental, pero con rasgos muy propios que la distinguían de Europa, porque ese mestizaje se vive como base de un nuevo ser. Así ha de leerse la raza cósmica de Vasconcelos, el indoamericano de Arguedas, la autoctonía de Tamayo, el mestizaje cultural de Uslar y corte de la realidad en Picón Salas.

\section{Mestizaje, universalismo y particularidad.}

Con la categoría geo - cultura es posible el acercamiento a una síntesis, necesariamente a la luz de la universalidad, que es requerida al interior de los estudios y balances del ser hispanoamericano. Por carecer la ciencia de un carácter meramente localizado, en un espacio territorial único, es que ha de recrearse dentro de la mundialización cultural. Proceso que cada día reviste mayor presencia en virtud de las industrias culturales y el papel que cumplen dentro de la globalización. La importancia de la categoría aludida, para aspaviento de los puristas y practicantes del imperialismo filosófico, es que nos permite elucidar el lugar de evocación. En términos generales, evocamos desde espacios o territorios geográficos específicos, así como desde territorios culturales que, si bien es cierto, son nacionales, han devenido en mundiales 
al amparo de la diversidad de las formas de comunicación, intercambio y circulación de ideas, conceptos, enunciados, representaciones, dentro del sistema mundo capitalista inaugurado en el siglo XVI.

El universalismo de la ciencia es un fenómeno moderno que guarda estrecha relación con el sistema económico mundial inaugurado en el siglo XVI. Wallerstein ha señalado que es uno de los logros del mundo moderno y comprende la aplicación de fórmulas y leyes generales en cualquier espacio y tiempo ${ }^{14}$. Por tener un fuerte ingrediente cuantitativo sus aplicaciones se pensaron podrían ser medidas. De ahí que se hablase de grados culturales, civilizacionales y de progreso. Los que desde la periferia capitalista alimentaron sus narrativas con este tipo de universalismo construyeron representaciones cargadas de inconformidad, desaliento y pesimismo, cuyo filón de ataque se encontró en la mestización indo - ibérica, al principio, a la que se agregaría el descendiente de africanos, posteriormente.

Sin embargo, como respuesta a este universalismo, de muy buen gusto para algunos modernistas del entretiempo que va de 1870 a 1930 en Latinoamérica, sería el romanticismo que con su fuerte carga bucólica estimularía la visión intramuros y la recreación de las tradiciones. El indigenismo que marcaría pauta posterior a la década del cincuenta (50), al menos el representado por José María Arguedas, de la centuria pasada se nutriría del realismo epistemológico, el economicismo y el marxismo, con lo que supuso la realidad indígena dentro de parámetros económicos y productivos contextualizados en la periferia del sistema mundo capitalista.

El indigenismo fue el equivalente andino al negrismo antillano y el revolucionarismo mexicano, tal cual lo propusiera el uruguayo Ángel Rama ${ }^{15}$. Quizá el mayor aporte, legado para

14 Immanuel Wallerstein, Análisis de sistemas - mundo. Una introducción (México: Siglo XXI editores, 2005), 60-61.

15 Angel Rama, La transculturación narrativa en América Latina (México: Siglo XXI editores, 2004), 70-73. 
la posteridad, enunciado por el peruano José Carlos Mariátegui sea el de haber propuesto el problema del indio en el contexto de una situación enmarcada en la dinámica propia del sistema capitalista de producción. Aunque por momentos desdibujada por su persistente disposición a asociar la salida de la expoliación y el empobrecimiento del indio, en la vanguardias esclarecidas, conectadas con el universalismo occidental y las clases medias emergentes.

Desde esta perspectiva, ya para 1910, el boliviano Franz Tamayo inauguraría el discurso acerca de lo autóctono ${ }^{16}$. Éste vino a significar una antítesis al discurso liberal de talante positivista, con el cual se intentó configurar el pensamiento racial más acorde con los cambios que se venían gestando en Bolivia, desde 1899. Proceso similar al experimentado por parte de letrados y académicos venezolanos, como Picón Salas y Uslar Pietri, quienes llegaron a proponer el mestizaje como un logro de la transculturación. Aunque Uslar Pietri prefirió utilizar mestizaje cultural en vez de esta última categoría, fue uno de los que nos legó las principales fuentes del mestizaje en los espacios territoriales reconocidos como Nuevo Mundo.

La ensayística de José María Arguedas referida al problema indígena vino a significar un rescate del mundo indígena alejada de todo patrimonialismo primordialista, disposición reflejada, a su vez, por su consideración del mestizo en tanto híbrido étnico con fuertes potencialidades de plenitud libertarias. En ningún sentido podría expresarse que Arguedas apreciara la cultura mestiza como una expresión superior, ante lo quebrantada de las poblaciones indígenas de Puno ${ }^{17}$, sólo que vio en el mestizo, el transculturado, mundialización cultural mediante, un actor social capaz de neutralizar las tentativas aculturadoras, así como el potencial preservador de los valores originarios indígenas. También, porque el mestizaje significó una expresión moderna, por tanto,

16 Javier Sanjinés, El espejismo del mestizaje. (La Paz, Bolivia: IFEA/PIEB/Embajada de Francia, 2005), 36.

17 José María Arguedas, Formación de una cultura nacional indoamericana (México: Siglo XXI editores), 2. 
civilizacional dentro de los grandes aportes para borrar toda bastardía de origen.

La apuesta por la transculturación, en tanto categoría de análisis y como parte del proceso histórico, le sirvió a Arguedas para demostrar cómo al lado de procesos de asimilación ajenos habían permanecido otros, con los que buscó demostrar la vitalidad de la cultura prehispánica. La organización social, las formas de economía, la religión, la estructura familiar, los bienes materiales de la cultura, el arte, habían sufrido cambios desde los tiempos de la conquista. No obstante, esa permanencia se había mantenido distinta a las propias manifestaciones culturales de Occidente. Para algunos estudiosos, esta sedimentada presencia de elementos indios llevó a considerar como peruano sólo al indio y sus costumbres originarias. Arguedas desmintió este aserto. Señaló, en este sentido, que la cultura europea e india habían convivido en un mismo territorio y en constante reacción mutua, “...en estos siglos, no sólo una ha intervenido sobre la otra, sino que como resultado de la incesante reacción mutua ha aparecido un personaje, un producto humano que está desplegando una actividad poderosísima, cada vez más importante: el mestizo..." ${ }^{\prime 18}$.

De igual forma, Mariano Picón S. llamó la atención de que haya sido el primer mestizaje el que proporcionó una gran fusión cultural. Este ensayista venezolano se valió de lo que llamó patrimonio acumulado, las artes y la lengua, para demostrar cómo la transculturación dio origen a lo criollo, a la cultura hispanoamericana. Hispanoamericana porque apreció que las diferencias de gentilicio propias de un nacionalismo cáustico y punzante, no impedían el reconocimiento de una realidad cultural condicionada entre las colonias ibéricas. El condicionamiento ha de leerse en los términos asociados con la transculturación. Esto es, que la realidad de la América hispana necesitaba de libertad económica y política dentro de nuevos requerimientos que comprendían la apropiación de ideas provenientes de Europa, pero cargadas de nueva y contagiosa pasión 18 Ibid. 
por alentarse en almas americanas, cuya característica principal estribaba en la propia de la transculturación o mestizaje cultural.

\section{Transculturación y mestizaje.}

El proceso transculturador y el mestizaje comprenden una serie de situaciones en las cuales es dable pensar no sólo en el enriquecimiento y la resemantización de los términos en juego, sino la posibilidad de que una serie de términos y categorías se saturen de inéditos contenidos. Lo que hoy para algunos suena como posmodernidad, en el sentido cronológico fraguado por los historiadores, demuestra un gran desconocimiento del devenir y sus enunciaciones. Porque si atendemos con detenimiento las propuestas acerca del mestizaje, vertidas por los autores considerados en esta oportunidad, se puede constatar que dentro de lo que en este último subyace se encuentra, principalmente, el hecho del enriquecimiento del contenido de algunos legados de la Ilustración, como las nociones de progreso, cambio, revolución, desarrollo, entre muchos más, los cuales se vieron alentados por las propias especificidades continentales.

Arturo Uslar P., buscó a su modo, contrarrestar la visión biologicista acerca del mestizaje. De ahí que prefiriera el uso de mestizaje histórico y cultural. En referencia con la idea de mestizaje cultural se adhiere la propia de Indiano, con la que Uslar intentó establecer esos rasgos comunes que definen toda identidad cultural. De acuerdo con Uslar fueron cuatro (4) fuentes las que contribuyeron con la conformación de aquel mestizaje. Junto con la fusión racial y cultural entre el español, el indígena y el africano, propuso un cuarto factor al que llamó Espacio nuevo. Éste fue el escenario donde se intentó hacer del indígena un labriego de Castilla. Fue el espacio al que se adjudicó nombres como el de Nueva España o Nueva Andalucía. Aquellos visionarios, 
los que impusieron estos nombres, creyeron poder imponer sus prácticas y relaciones sociales en territorios muy ajenos a los propios de su nativa España ${ }^{19}$.

Al tomar en consideración lo que Uslar denominó espacio nuevo, agregó un nuevo factor de interpretación que para muchos, positivistas y evolucionistas, constreñían el desasosiego y una suerte de parálisis hacia un nuevo orden y el encuentro con el progreso y la civilización. Uslar tomó distancia de toda interpretación determinista, no sólo la consagrada al espacio natural, también de suyo lo haría respecto al espacio económico. Su interés estuvo centrado en la herencia de hábitos y costumbres arraigadas en un tiempo largo, y condicionadas por estructuras morfológicas, orográficas y físicas, no como determinantes en última instancia, sino como condicionamiento que estimuló un ritmo de desenvolvimiento a la dimensión cultural.

No fue sólo este condicionamiento el que concitó la emergencia de una identidad conflictiva. Quizá, el mayor peso lo tuvo el traslado al calco de instituciones y prácticas políticas que funcionaron, a su modo, en la Península ibérica, no así en los espacios que Cristóbal Colón adjudicó a Asia. Aquí entra en juego la noción de visionario - compendiado en la historicidad de un pensamiento - con la que Uslar buscó enlazar la impertinencia de visiones y realizaciones, cuyo propósito ha sido el de definir y representar el Nuevo Mundo, de acuerdo con las formas políticas adoptadas en una realidad cultural muy distinta a la fraguada en Europa.

La importancia otorgada a la historia, como narrativa y análisis, estriba en la facultad comprendida en ella, como lo es su capacidad para dar cuenta de lo acaecido en el Nuevo Mundo y el estudio de lo que Uslar denominó mestizaje cultural. Porque en este proceso es posible el encuentro con la identidad hispanoamericana y latinoamericana. Al proponer este mestizaje como hecho de múltiples manifestaciones las cuales se han mantenido en un tiempo

19 Arturo Uslar Pietri, Godos, insurgentes y visionarios (Barcelona, España: Seix - Barral, 1986), 22. 
largo, pretendió establecer el carácter inacabado de los procesos culturales continentales. La completud necesaria de estos procesos los vio cristalizados en Europa y los Estados Unidos de Norteamérica, inclusive en algunos espacios territoriales de África y Asia. Desde este ángulo, llegó a proponer que muchas de las circunstancias que habían provocado la experiencia, en el seno de lo que se denominó identidad conflictiva, se asociaban con la falta de una articulación entre los cuatro factores de la nacionalidad en el Nuevo Mundo.

Una proposición similar fue configurada por Picón Salas, alrededor de los años treinta del siglo pasado, para quien Hispanoamérica formaba parte del mundo occidental, amén de su inclusión mediante los procesos de colonización y conquista. Pero, también lo era en virtud de haber consumado sus procesos de independencia con ideas que provenían del viejo continente. Ideas que sufrieron o fueron objeto del mestizaje o la transculturación. Sin embargo, el proceso de fusión y de compactación cultural no había logrado cristalizar en estos parajes, tal como había logrado fusionarse en Europa. De ahí que le interesara destacar la actitud enigmática con la que convivían los actores sociales hispanoamericanos, es decir, los altibajos representados en las actitudes supeditadas a la disimilitud y la alteridad, propias de toda disposición identitaria.

No se puede decir que Uslar apreció en América una simple prolongación del Viejo Mundo o, en todo caso, de Europa. Más bien la relacionó con una consecuencia inevitable de la expansión de un sistema productivo y de acumulación. Aunque no llegó a utilizar estos conceptos, si dejó entrever que la proeza conquistadora, perpetrada desde la Península Ibérica, formó parte de los requerimientos de mercaderías en un momento de expansión del sistema mundo capitalista. En letrados como José María Arguedas y Mariano Picón Salas la realidad continental que éstos vivieron y experimentaron, puede ser asociada con un sistema - mundo que se fue integrando a partir del siglo XVI, desde el que es posible estudiar, comprender, analizar, al 
mestizo. Aunque las referencias respecto a la idea de pueblo y cultura nacional se veían envueltas en un desenvolvimiento por cristalizar. De ahí los conflictos suscitados alrededor de la identidad y el ser hispanoamericano.

Desde esta perspectiva, Arturo Uslar Pietri asoció la creación de Nuevo Mundo con mutación, traslado y alteración de Occidente. La idea de mutación de la civilización occidental refiere su carácter de excepcionalidad, plagado de diversidad, pero que no logró cristalizar en lo que se pensó sería una fuerte síntesis cultural. Por esto, América Latina no vendría a representar una superposición, sobreposición, o simple añadido de elementos culturales unos sobre otros tal como sucedió con algunos espacios territoriales de África y Asia. Latinoamérica sería la representación cultural de una fusión creadora, desde donde es dable inferir un hecho cultural inédito y novedoso. La cultura en estos parajes se convirtió, por este intermedio, en un mundo sui generis. Uslar no propuso una visión de lo cultural como una expresión o fiel reflejo de Occidente, porque nuestro continente es parte del Hemisferio Occidental pero en una condición distinta. Al igual, otros letrados, académicos e intelectuales, como Arguedas o Picón Salas configuraron en sus narrativas una visión de América Latina en tanto potencialidad ante las realizaciones euro norteamericanas.

Un caso emblemático, en este orden, puede corroborarse en los planteamientos del mexicano José Vasconcelos para quien el mestizo representaba una nueva síntesis cultural. Síntesis que lo indujo a proponer que los procesos de fusión e intercambio cultural, suscitados al interior de Hispanoamérica, serían las bases de una nueva plenitud, donde bien cabría la cristalización de una inédita civilización. En este orden, debe tenerse muy en cuenta que el tiempo que tomo como trasfondo, en especial, los primeros cincuenta (50) años del siglo XX se 
encontraba un convencimiento sustentado en la creencia de que todo desenvolvimiento debía tener una cristalización, un corolario, los que se asociaron con síntesis.

Vasconcelos basado en las tesis mendelianas, propuso la superioridad de la raza cósmica ${ }^{20}$. Su tesis la sustentaría en que el hibridismo en el hombre, al igual que en las plantas, tiende a la reproducción de mejores tipos y alienta hacia el mejoramiento de lo que se había vuelto estático. De acuerdo con este pensador mexicano, el mestizo y el mestizaje eran hechos ciertos. Además apreció que el mexicano y el latinoamericano contenían una gran vivacidad mental y una disposición anímica mucho más amplia que la de sus predecesores. Vasconcelos sería parte de una tradición, que se puede visualizar en México, donde, desde mediados de los años cincuenta del decimonono, Juan Álvarez, el padre del Plan de Ayutla (1854) haría ingresar al mestizo como la representación cultural y étnica mayoritaria del país Mesoamericano.

\section{Conclusiones.}

Ya sea Indoamérica, Hispanoamérica, Latinoamérica, Mestizoamérica o el Nuevo Mundo su constitución se enlaza con Occidentalidad. El enlace se conjuga con la génesis de este espacio territorial en Europa. Sus particulares características culturales son la base para definir al Nuevo Mundo como un espacio occidental sui generis. De cuyo seno surgieron voces que propugnaban una forma de originalidad, bajo el influjo occidental, pero reconociendo lo que de particular emergería en América, como inédita experiencia de intercambio racial, social y cultural, como lo fue el mestizaje. El reconocimiento de este último no puede ser considerado como una simple respuesta al biologicismo positivista, sino como una respuesta ante las nuevas formas de colonialismo en boga.

Marcas, hitos, como los de 1898, 1903, 1918 y la guerra entre 1914 y 1945 estimularon

20 José Vasconcelos, Obra selecta (Caracas, Venezuela: Biblioteca Ayacucho. № 181). 
nuevas formas de ver el sistema mundo, donde el espacio cultural venía adquiriendo inéditas connotaciones que sirvieron de base para nuevos contenidos de la noción de mestizaje. Los letrados e intelectuales aquí tratados se apropiaron de enunciados, conceptos, representaciones, emanados de acontecimientos como los suscitados alrededor de la independencia tutelada de Cuba, la emergencia como nación independiente de Panamá y la Primera Guerra Mundial y la Segunda Guerra Mundial, con la que se cerró el abanico abierto, a partir del siglo XVI, en el sistema mundo capitalista, centrado en la posesión colonial. Ante estos acontecimientos hubo reconocimientos e identificaciones. Lo cierto, de lo aludido con anterioridad, comprende un conjunto de configuraciones acerca del ser hispanoamericano en diversos momentos del siglo $\mathrm{XX}$, tal como lo refieren los conceptos de transculturación y el enriquecimiento, en términos positivos, de la idea del mestizaje. También, lo sería lo propio respecto a la noción de pueblo y cultura, en los que se llegó a reconocer un legado, una historia, en conjunción con nuevas síntesis de los mismos.

No obstante, estas elucubraciones no tuvieron impacto directo en las comunidades que fueron objeto de análisis e inspiración argumental, tal como ha sucedido con las diversas narrativas impugnadoras del orden establecido. Quizá esta situación se deba a su fuerte disposición occidentalista a la que, a su vez, se ha buscado contrarrestar con el mismo utillaje teórico - conceptual. El tema indígena, por ejemplo, sirvió como referencia para el enaltecimiento del mestizo, en tanto portador de la plenitud libertaria, igualitaria y democrática. También, el utillaje literario y conceptual en uso para este cometido fue tomado de los recursos propios de la cultura mestiza y los propios divulgados amén de la mundialización cultural, en los que se encumbró la imagen del llanero y del obrero, como virtuosidad plena, al menos en Venezuela. La reterritorialización de ideas y enunciados provenientes de esta realidad ofrece, ostensiblemente, 
la hibridación de algunas propuestas avenidas con el universalismo, como lo fue la superación de un aspecto de la noción de civilización y el avenimiento con la idea de cultura y sus diversas expresiones temporales y territoriales.

Creo que el mestizaje tanto como constructo académico, así como su dinámica práxica, no ha tenido la suficiente atención por parte de historiadores, antropólogos, sociólogos y ensayistas. Sólo su fuerte adhesión con la raza y su concomitante corolario geno - fenotípico ha recibido cierta atención, no siempre feliz, por parte de evolucionistas, darwinistas sociales y positivistas. Quienes, más bien, ofrecieron un panorama ontológico del continente cargado de culpas y deficiencias las cuales se han orientado hacia el estudio del origen feno-genotípico y el determinismo geográfico. Asimismo, estas disposiciones parecen ser la fuente informativa más cercana, y con la que parecen alimentarse nuestros intelectuales cercanos al último liberalismo de los setenta del siglo XX.

Por lo general, las palabras, conceptos, enunciados se van llenando de nuevos contenidos. No siempre fáusticos y venturosos. Así ha sucedido con el de transculturación, asociado sólo con imposición, desculturación y aculturación; el de cultura, aunque con mayor suerte porque al lado de su asociación con patrimonio, academia y bellas artes se ha combinado con el de red de significados; el de ciudadanía endosado sólo con la esfera política; el de democracia en consonancia sólo con el capitalismo; el de mestizaje como expresión orgánica, aunque alimentado con elementos culturales y sociales en las narrativas de José María Arguedas, Franz Tamayo, José Vasconcelos, Mariano Picón Salas y Arturo Uslar Pietri, entre otros

A su manera, estos letrados y ensayistas sortearon el fuerte escollo biologicista, aunque alejados con vigor de toda disposición socialista de la que no fue ajeno Arguedas. Este abrevó en el grupo que giró en torno a la revista peruana Amauta. Allí vivió las proposiciones del 
socialismo y las propuestas mariateguianas en torno al indo - hispano. De igual modo, le correspondió ofrecer no sólo un panorama de la transculturación y su corolario cultural más fuerte, el mestizo. Aunque, según palabras de Rama, el acercamiento de Arguedas al mestizo no lo ejecutó alejado de inquietudes y sospechas. Lo veía con desconfianza por su antiheroicidad y sus escasos compromisos colectivos, lo que lo hizo pensar en actores sociales de escaso tenor moral $^{21}$. Sin embargo, apreció en la cultura mestiza, su propio mundo cultural, la salvaguarda de un pasado que se había enriquecido con el intercambio desigual y combinado bajo el influjo de la conquista, colonización y evangelización ibéricas. También otorgó gran importancia a la visión del tiempo asumido entre las culturas orales y las escritas, mientras en las primeras predominaba una temporalidad en forma de ciclos, como el mito Inkarrí, y las escritas, de corte occidental, donde el tiempo es lineal, tal cual cómo se ha mostrado en la historia denominada universal. Historia a la que Picón Salas y Uslar Pietri reclamaron en sus configuraciones un lugar para la América Hispana o Nuevo Mundo. Si bien es cierto no como mera prolongación o sobreposición, si como expresión enriquecedora de la misma, lo cual se evidenciaba en las potencialidades culturales contenidas en el mestizaje continental.

En términos generales, pudiera argüirse que las disposiciones narrativas tramadas por José María Arguedas estuvieron enmarcadas en el indigenismo y la fuerza civilizadora de un mestizaje donde el indígena, lejos de debilitarse culturalmente, encontraría nuevos cauces de plenitud. De igual manera, las respuestas del hispanismo latinoamericano, donde bien pudieran ubicarse las narrativas de Franz Tamayo, José Vasconcelos, Mariano Picón Salas y Arturo Uslar Pietri, se configuraron ante el monroísmo - panamericanismo, propulsado desde los Estados Unidos de Norteamérica, y el indigenismo. Para estos letrados el mestizaje sirvió como una representación de la modernidad, con lo que, a su vez, buscaron todo alejamiento de las 21 Rama, 186. 


\section{IX) conctuss

propuestas del indigenismo en tanto referente inicial de identidad. El hispanismo, dentro y fuera de América Latina, representó e imaginó los peligros, especialmente en términos culturales, representados en el expansionismo del coloso del norte. Lo cierto de todo esto es que la afanosa búsqueda por encontrar las huellas iniciales de la identidad, no sólo se ejecutaron con el utillaje teórico - conceptual elaborado en Occidente, también hizo suyo la necesidad de conjugar una genealogía con la cual explicar el origen de la excepcionalidad del Nuevo Mundo, donde las adherencias culturales del mestizaje sirvieron de gozne entre un requerimiento narrativo y el proceso histórico, el de los hechos brutos. 